\title{
Taguchi Method and Taguchi-Pareto Scheme to Evaluate Diffusivity during the Development of Orange Peel Epoxy Composites
}

\author{
Oluwaseyi Ayodele Ajibade , Johnson Olumuyiwa Agunsoye ${ }^{a}$, Sunday Ayoola Oke ${ }^{b, *}$ \\ ${ }^{a}$ Department of Metallurgical and Materials Engineering, University of Lagos, Lagos, Nigeria \\ ${ }^{b}$ Department of Mechanical Engineering, University of Lagos, Lagos, Nigeria
}

\begin{abstract}
The evaluation of diffusion parameters of orange peel epoxy composites is currently crucial as they explain the movement and elimination of waste from the cells with important implications for the expected lifespan of the composite material. However, existing diffusion methods are unreliable as they yield sub-optimal designs, avoids the benefit of reduced cost of experimentation and extreme flexibility in composite designs, which can accommodate several design factors. Consequently, in this paper, the idea is to account for parametric optimization of composites in the classical Taguchi and prioritized parametric (Taguchi-Pareto) forms. An $L_{16}$ orthogonal array was considered. Experiments were conducted in two sets with three and seven days intervals while the initial and final weights and the thickness of composites were measured. The optimal parametric setting for the three and seven days of diffusivity are both $P_{4} Q_{4} R_{1}$ interpreted as $11.69 \mathrm{~g}, 13.73 \mathrm{~g}$ and $0.0224 \mathrm{~m}$ (for three days) and $11.69 \mathrm{~g}, 15.04 \mathrm{~g}$ and $0.0221 \mathrm{~m}$ (for seven days), respectively. These are for the initial weight, final weight and the thickness of the composites, respectively. By the Taguchi-Pareto method, the optimal setting leaves out the thickness parameters because it is not significant to optimality, confirmed by analysis of variance which showed that the thickness parameter is of less significance. The benefit of this attempt is to help composite manufacturers the commercial decision in design optimizations and produce low-cost composites.
\end{abstract}

Keywords: Orange Peel Epoxy Composites, Optimization, Taguchi, Diffusivity, ANOVA

\section{Introduction}

A foremost practice in the evaluation of diffusion parameters of composites concerns the association of the internal mechanical states undergone by the matrix, the reinforcing material's absorption capacity and the environment [1-5]. For the orange peel epoxy composites, these parameters explain crucial movement and elimination of waste from the cells and have important implications for the expected lifespan of the composite material $[6,7]$. However, existing diffusion methods are unreliable as they yield sub-optimal designs. But designing and developing orange-based composites at optimal conditions permits a reduced cost of experimentation a statistical tool estimates the parameters with lesser experimental runs [8-11]. Furthermore, seeking optimal conditions to designing composites allows the designer to adapt multiple factors into the design for design robustness [9-10].

Nowadays, there is an emerging trend for continuous innovation in the composite industry [12]. The industry is seeking for sustained lightening of industrial parts, improved performance of

\footnotetext{
* Corresponding author.

E-mail address: sa_oke@yahoo.com

Manuscript History:

Received 5 February, 2021, Revised 27 April, 2021, Accepted 29 April, 2021, Published 30 April, 2021
}

e-ISSN: 2289-7771 
reinforcement and the extended lifespan of composite structures in use [13]. Thus, in this paper, the Taguchi method and Taguchi-Pareto methods are proposed as new methods in the context of diffusion parametric estimation to account for the parametric setting in both prioritized and non-prioritized forms of composite parameters for improved performance of reinforcements.

Accordingly, this study applies the theory of Taguchi methods to evaluate and update the current knowledge on diffusion parametric evaluation [8-11]. The first phase of Taguchi methodical application is a theory that provides a technique to evaluate the diffusion parameters of orange peel based composites by the establishment of the representative factors from the diffusion process [8]. This is followed by the definition of levels, orthogonal matrix, signal-to-noise quotients and the optimal parametric setting [9]. The second phase of the Taguchi method called the Taguchi-Pareto method is based on the theory of analysis of variance that establishes the most influential factors by variance [10]. Then the Pareto theory of 80-20 rule is applied [11]. This study is important since it has the features to determine the significant deficiency of optimal parametric settings in diffusion parametric evaluations. Besides, it provides important information to composite development and design workers on the basic composition of an optimization-based diffusion method. Moreover, by utilizing and establishing the research gap that has remained unexploited for years, future research on the diffusion process is stimulated. Based on the foregoing, the contributions of this paper to the diffusion process literature are stated as follows:

- Stressing the evaluation parameters and features of the Taguchi method and Taguchi-Pareto method, which had remained unclear in previous research and use the method to derive the optimal parametric settings in both the prioritized and non-prioritized forms of the diffusion parameters

- Establishing research deficiencies on diffusion process methods in orange peel composites to strengthen future research pursuits in the area.

- This study assists composite developers, particularly those in the design for structural integrity, to take optimal decisions on diffusivity issues before designing orange peel reinforced composites for fabrication.

- This study focuses on particulate orange peels and the obtained results may be used in hybrid epoxy composites consisting of multiple reinforcements out of which orange peel particulates may be a constituent.

- This research activity analyzes multiple parameters to the optimization of diffusivity of orange peel particulates, namely, initial weight, thickness, and diffusion constant.

\section{Literature review}

\subsection{General}

In this section, articles are reviewed to offer a clear view of what has been implemented in the composite literature and this reveals the important gap that the current article bridges. It is a common practice in the orange peel composite literature to address the mechanical aspects of the composites. Mechanical properties are the physical properties of the material that are measurable when forces are applied. Consequently, researchers sought to understand the tensile strength, fatigue limit, modulus of elasticity, hardness and elongation of composites among other properties. The motivation for studying mechanical properties is to establish the scope of the usefulness of the composite material and determine the expected service life of the composite. The most frequently cited sources include Awasthi and Saxena [7] that considered the following aspects: hardness test, and tensile strength. The optimum hardness was obtained at 20\% fiber volume, which ranged from 261 to $234 \mathrm{HV}$ and concurred with a value of $251 \mathrm{HV}$ obtained by Anoopisan et al. [14] for 30\% fiber volume content of orange peel composite. 
Other sources that analyzed the mechanical properties of the orange peel composites are Ojha et al. [15], Aigbodion et al. [16] and Anoopisan et al. [14]. From a mechanical property evaluation perspective, a composite should aim at attaining elongated life-spans with high guaranteed load attributes that guarantee load and important resistance among other important mechanical attributes of the composite. Nonetheless, a slow-growing effort has been directed at the water absorption and diffusivity studies of orange peel composites in recent times.

The aspect of the study by Aigbodion et al. [17] concerns the kinetics of Isothermal degradation where the properties of the orange peel ash composite were studied for deterioration. The issues analyzed include the surface morphology of the composite revealed by the results of the scanning electron microscopy (SEM) and the energy-dispersive X-ray spectroscopy that analyzed the surfaces of the samples. The advantage of pursuing the scanning electron microscopic analysis by the authors was, threefold. First, it enabled a reliable and useful comprehension of the surface topography of the composite. Second, it is useful to differentiate between the surface textures of the composite. Thirdly, it permits the scrutiny of the grain boundaries in a sample containing unattached samples. Another issue considered is the thermal stability that was analyzed using the differential thermal analysis and the thermogravimetric analysis. Furthermore, they considered the kinetics of the thermal decomposition for the composite using the models given by the Elynn-Wall-Ozawa and the Kissingers model. While this study is relevant and heightened the ideas behind the kinetics of the thermal decomposition for the orange peel composites, what remains open for research is the aspect of optimization of the properties of orange peel composites. The Taguchi method and the Taguchi-Pareto scheme have not been deployed to optimize the properties of the orange peel composites.

The aspect of work by Aigbodion et al. [16] concerns the carbonization of orange peel particles and the high-density polyethylene was deployed as the matrix. The issues analyzed include particle size analysis, carbonization of orange peel particles, the use of scanning electron microscope on samples, a tensile test of composites, bending strength, hardness test and impact test of composites visual observation of composites, and morphological analysis of composites using the energydispersive X-ray spectroscopy. The key insights of this article are the argument that uncarbonized orange peel particulates revealed outstanding higher and preferred performance to carbonized orange peel particulates in tensile strength, bending strength, and capacity to withstand impact force. Notwithstanding, the carbonized orange peel particulates exceed uncarbonized orange peel particles in hardness performance. By following the pathway of carbonization and uncarbonization of orange peel particulates using the high-density polyethylene as a matrix, diffusion studies wherein the composites may be immersed in water may be studied. However, what could the optimal values of studied parameters be? Will they be different from the reported values of sub-optimal measurements? Unfortunately, no insight has been given in literature on this issue and the usefulness of the Taguchi scheme and the Taguchi-Pareto scheme in solving the problem is not known.

The aspects of Anoopisan et al. [14] concern the interfacial characteristics of the composites. The issues analyzed include density, tensile strength, beam test and hardness measurement. It interests the researcher to note that the $20 \mathrm{wt} \%$ of the orange peel composite exhibited noteworthy performance in the various tests, including the tensile test and flexural test. This agrees with the results of tensile and flexural tests of Praveenkumar and Nagaraj [18]. However, it disagrees with the results of the hardness test which Praveenkumar and Nagaraji [18] reported as 20\% particulate composite compared with it that shows a $30 \mathrm{wt} \%$ of composite. Furthermore, there is concurrence in the reported densities of the two composites tested in Praveenkumar and Nagaraj [18], which reported 1.082 to $1.225 \mathrm{gm} / \mathrm{cm}^{3}$ and that of Anoopisan et al. [14] that reported a density range of 1.012 to $1.225 \mathrm{gm} / \mathrm{cm}^{3}$. The key insight of this article is that the experiment produced an outstanding tensile strength of $27.87 \mathrm{MPa}$ for the particulate orange peel composite. Unarguably, it exceeds the reported range of result by Praveenkumar and Nagaraj [18], which had a maximum value of $25.85 \mathrm{MPa}$. Surprisingly, as Anoopisan et al. [14] reported, the obtained value of tensile strength exceeds those of kenaf, acacia, water hyacinth, banana and empty fruit bunch of 16.85, 13.03, 14.72, 16.18 and 13.61, MPa, 
respectively. Nonetheless, in a water environment, these values could change but this has not been tested to the best of our knowledge of composite literature. But of prime interest are the optimization values when the Taguchi method and Taguchi Pareto method are tested with the diffusivity experimental results. Thus this is a gap regarding the optimization of diffusivity parameters using the Taguchi scheme and the Taguchi Pareto method while the focus composite is the orange peel particulate composite.

The aspects of Praveenkumar and Nagaraj [18] concern the mechanical characterization of orange peel powdered composites. The issues analyzed include density measurement, hardness test, tensile test, flexural strength, and the scanning electron miscopy. The key insight of this article is that the $20 \%$ particulate content showed extraordinary performance in several test results including tensile test flexural test and hardness test. Interestingly, to confirm the superiority of the $20 \%$ fiber contents over the other contents of $0,5,10$ and $30 \%$ fiber contents, the scanning electron microscopy indicated acceptable attributes of the composite when examined under the microscope. There was a complete absence of fiber dipping-out, debonding and crack formation, confirming a strong bonding between the matrix and the reinforcement. However, it is possible to consider the condition outside the dry environment with which the experiment was conducted. By immersing the $20 \%$ fiber content orange peel composite in water its performance may be studied but the interest is the determination of the optimal values. This has not been studied previously. More interesting is the absence of the Taguchi method and Taguchi-Pareto scheme, which the literature has failed to report regarding orange peel particulate composites.

Novel research in orange peel composite development is credited to Karthikayan et al. [19], which considered the following aspects in the article tensile test, flexural test, inter-laminar shear strength, compression test and impact test the key insight of this article is the argument that $30 \%$ fiber composite exhibits the most noteworthy evaluations in several aspects of the mechanical test while the $35 \%$ fiber content orange peel composite display that in tensile test flexural tests. The evidence was displayed that in the tensile test, flexural test inter-laminar shear strength, compression test and impact test, the most noteworthy evaluations were respectively displayed as $40 \%, 30 \%, 35 \%, 30 \%, 30 *$ and $40 \%$ fiber content orange peel composite. This means that the overall basis, in all the mechanical test the $30 \%, 35 \%$ and $40 \%$ fiber content orange peel composites have $60 \%, 20 \%$ and $40 \%$ most noteworthy evaluations for all the tests including tensile test, flexural test, inter-laminar shear strength, compression test and impact test. By benchmarking these results with the literature, the recent article disapproves the results reported by Praveenkumar and Nagaraj [18] on a tensile test that declared a $20 \%$ fiber content noteworthy as against a $40 \%$ fiber content orange peel composites declared by Karthikayan et al. [19]. The differences may be due to different species utilized by the researchers. Yet this is still questionable as both studies were conducted in India where little variations in species of the orange may occur. This unclear situation needs to be verified in future experiment another possibility for the difference is the error introduced in the equipment usage still future experiments may reveal this challenge or disprove it. But even the results of $40 \%$ fiber content orange peel composite reported by Karthikayan et al. [19] on the tensile test can be contested as Anoopisan et al. [14] earlier reported the most noteworthy tensile test evaluation as $20 \%$ fiber content orange peal composite.

\subsection{Studies on water absorption}

Several attempts have been made to describe the water absorption behaviour of composites [20]. There have been attempts to explore the use of fibers as fillers, the use of jute, hemp, sisal and kapok (among others) as the range of waste products examined and the use of the amount of water uptake and Fickian models as major parameters for water absorption evaluation. A large array of investigators on composites seem to have utilized fibers as the filler material such as hemp [21], recycled cellulose [22], sugar palm [23], jute fiber and with combinations of other fillers [20, 24-30], 
banana [31], cotton [32], oil palm empty fruit branch [33], Pennisetum purpureum [34], wood [35], flax [36], sisal [37], wood-plastic [38], glass fiber [39] and aluminium particles [40].

Furthermore, many attempts have been made to study a wide range of biodegradable materials and/or with synthetic materials in isolation or hybrids jute, sisal, hemp, kapok, recycled cellulose, flax, kenaf, wood, recycled newspaper, coconut, cotton fabric, oil palm, sugar palm [21, 41-42]. There have been attempts to explore the mechanical property changes of hemp due to hybridization and compatibilization [43], processing characterization and properties of hemp fibers [44].

Also, accounts of water absorption process investigations have been given for several years by many investigators wherein the concerns have been the use of diverse ratios. The numerous ratio used for water absorption process measurements are majorly the amount of water intake, Fickian measures [22], percentage of absorbed moisture [45], thickness swelling, volume swelling, water absorption percentage, relative density [20], weight difference, Fickian measures [46].

\subsection{Summary of the literature review}

Following the literature review, the evidence from various reports reveals that:

1. Several investigations have been conducted using the usual (only orange peel particulates) reinforcements and combined reinforcements (such as orange peel particulates and coconut shell particulates) to reinforce both epoxy resin and high-density polyethylene as a matrix in individual reports.

2. The epoxy resin is more widely used as a matrix than high-density polyethylene.

3. Researchers have shown interest in the carbonization of orange-peel particulates to reinforce the high-density polyethylene matrix and compared results with uncarbonize composites.

4. The most common aspect of research on orange peel composite is the experimental analysis on mechanical tests with very scanty literature sources on diffusivity, however, reports that incorporate diffusivity have been conducted only for combined reinforcements of orange peels and coconut shell in particulates form.

5. The aspects of mechanical tests conducted are the hardness test, tensile strength, impact test, flexural test and inter-laminar shear test.

6. There is no study targeted at optimization that used the Taguchi Scheme and Taguchi-Pareto method on orange peel composites.

7. A third aspect of the body of research on orange peel composite research relates to the kinetics of isothermal degradation. However, scanty reports were made on this aspect.

8. There is substantial potential for quantitative studies especially modelling and simulation on orange peel particulate composite studies.

9. A broad range of studies has been conducted on epoxy-based orange peel composites in both the particulate and fiber-based filler categories.

10. Diverse investigators have largely given attention to the mechanical as well as metallurgical properties of epoxy-orange peel composites.

11. The use of particulate orange peel filers is very limited.

12. Very few studies have directed attention to Taguchi methodical optimization in the water absorption process.

Furthermore, among the several methods that could be deployed to examine the optimal behaviour of parameters regarding water absorption (diffusivity) in orange peel composites, the target of this work is the Taguchi methods that comprise the Taguchi scheme and the Taguchi-Pareto scheme because of their capability to evaluate parameters with the least experimental cost possible, ability to interprete information from the method (Taguchi scheme) in both quantitative and qualitative dimensions, and the ability to Taguchi-Pareto method to prioritize parameters for economic 
gains of the process. Such models have been applied in different areas of research including maintenance and composite development [8-11]. In the Taguchi-Pareto method, the analysis of variance is used to set the contribution based on the variance analysis of each parameter. The variance values are ordered from the highest to the least and the Pareto rule emphasizes an 80-20 analysis whereby $80 \%$ of the parameters by variance value are taken as essential for analysis. The proposed methods of Taguchi and Taguchi-Pareto schemes have been designed to assess the diffusivity of the orange peel epoxy composite and thus limited to the analysis of results obtained from water absorption (diffusivity) that follows the Fickian's diffusion model of water absorption. Arising from the above insights, it was decided to investigate the diffusivity of orange peel composite with a focus on optimization using the Taguchi scheme and Taguchi-Pareto method to bridge the important knowledge gap of optimization in orange peel particulate composite development. 


\section{Materials and Method}

Figure 1 shows the schematic of the research from conception to composite manufacture.

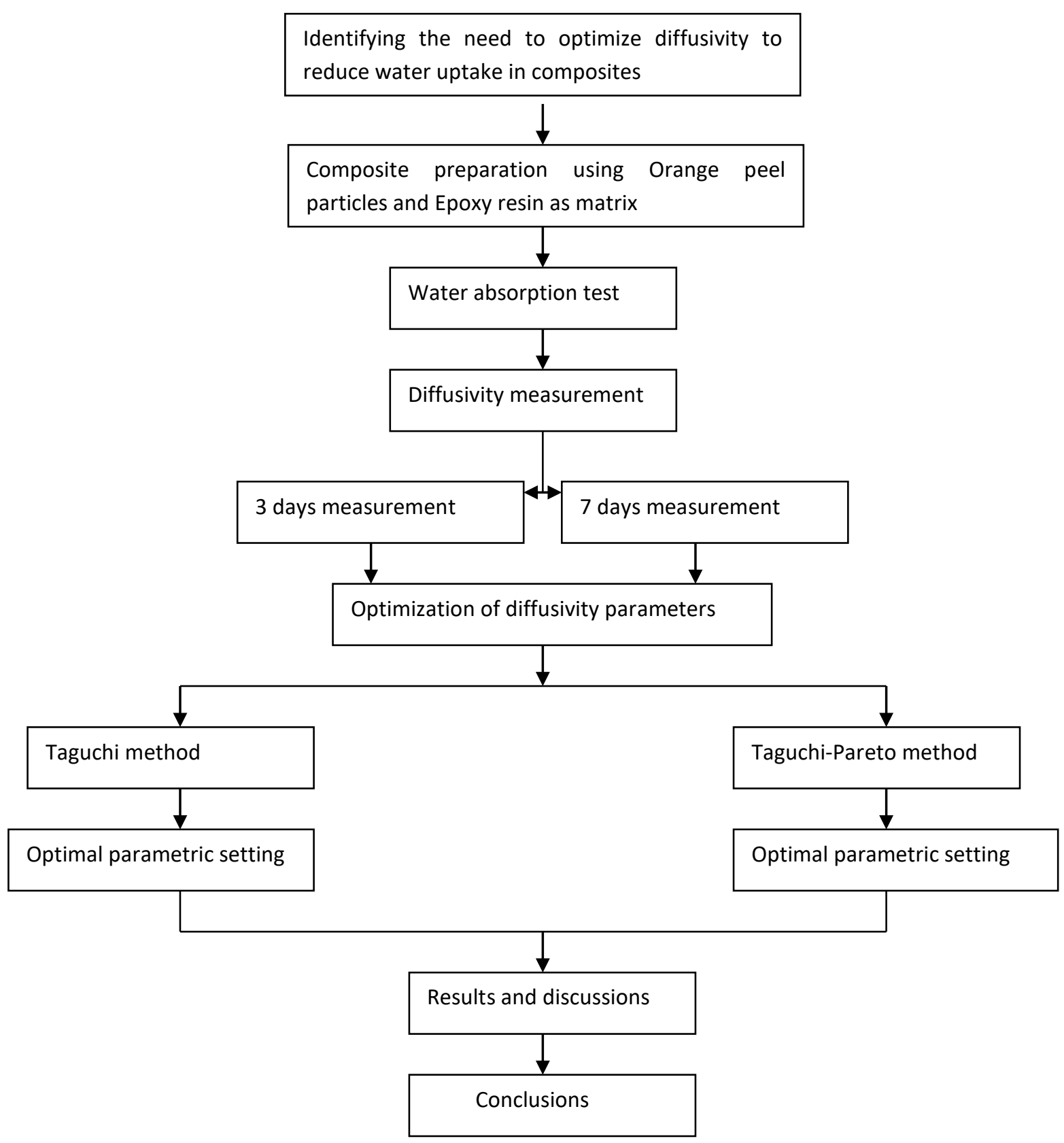

Figure 1. Research scheme for optimization of diffusivity parameters

\subsection{Materials}

Orange peel wastes have been collected from local retailers of oranges in Oyingbo, Bariga and Akoka market areas of Lagos State, Nigeria. The orange peels come in greenish-yellow colouration and are moist due to the presence of water and oils. The orange peels were processed by sun-drying to remove moisture and oils from the peels. Drying was observed complete after a change in colouration of orange peels from greenish-yellow to brownish and the texture of the orange peels became crisp. 
The dried orange peels were pulverized and ground to particulate form in local grinding mills. Sieve analysis of the particles was done using a British standard test sieve (Wykeham Farrance) and 0.600 $\mathrm{mm}$ particle size was used for the current investigation. Furthermore, from the extant literature, orange peels used in composite fabrication do not necessarily require chemical treatment because it has been dried to remove moisture and it has also been ground into particulate. Consequently, it has also given excellent reinforcement performance in composite fabrication. A literature supporting evidence is Ojha et al. [15] that examined the mechanical properties of orange peel particulates as reinforcements in epoxy composite fabrication.

The epoxy resin used is the Diglycidyl Bisphenol A, which was obtained locally from Tony Nigeria Enterprises, a chemical marketing company based in Lagos state Nigeria. The epoxy resin is labelled as the LY556 while the hardener used in the study is labelled as the HY951. However, the choice of epoxy resin and hardener is consistent with the literature, as demonstrated in Ojha et al. [15]. Furthermore, the matrix material employed in the current investigation, epoxy resin, is also known as Diglycidly Bisphenol A. As indicated in Prabhakaran [47], the dighlycidly ether of bisphenol A (DGEBA) is structured to possess two groups of epoxides, which are located at each end of a molecule. Further processing involves the mixing of DGEBA with diluents to minimise the viscosity of the output. Then the cured epoxy matrix is treated with flexibilizers to enhance its impact strength. Besides, a small quantity of a reactive curing agent is added to initiate a polymerization reaction that transforms that liquid resin into the solid phase before adding fibers into the liquid matrix mixture [47]. In concurrence with the report by Prabhakaran [47], the main attraction to the use of the chosen epoxy resin includes the following. First, it helps to retain the powdered orange peels in position. Second, it serves as a medium of stress transfer among the particles of the orange peels. Third, the epoxy resin is very effective in resisting unfavourable environment such as water and could resist moisture as well as chemicals. Fourth, the matrix has also been found as a very effective shield since the surfaces of particulate orange peels are protected from mechanical degradation such as abrasion [47].

\subsection{Composite preparation}

Pure epoxy and its hardener were mixed thoroughly in the ratio 1:0.7 to ensure homogeneity and faster curing. Epoxy resin was combined at room temperature with OPPs in 5, 10, 15, 20, 25, 30 and 35 vol. \%. Furthermore, Ojha et al. [15] established four composite weight fractions of 5, 10, 20 and $30 \mathrm{wt} \%$ and this work followed the convention by allowing the range of the weight fractions of composites to from 5 to $30 \mathrm{wt} \%$. However, it is found more interesting to expand the current range of composite weight fraction beyond Ojha's proposal on both sides of the lower and upper boundaries of $5 \%$ and $30 \%$ to include $0 \%$ and $35 \%$. Thus, the choice of the composite weight fraction in the present article is more robust than Ojha's choice. This is expected to be more accurate than Ojha's proposal. As a result, seven classes of composites with pure epoxy as the control sample were prepared as specified by Table 1. Each sample of the mixture was thoroughly mixed to obtain a homogenous whole, before pouring carefully into a prepared mould. The mould was fastened securely with four Gclamps while the material was allowed to cure for 24 hours before removal. 
Table 1. Relative amount (vol \%) of OPPs filler and Epoxy resin matrix in the OPPs/Epoxy composites

\begin{tabular}{|c|c|c|}
\hline Filler (\%) & $\begin{array}{c}\text { Matrix } \\
(\%)\end{array}$ & Composites \\
\hline None & ER: 100 & Control sample \\
\hline OPP: 5 & ER: 95 & $5 \%$ OPP/ Epoxy \\
\hline OPP: 10 & ER: 90 & $10 \%$ OPP/ Epoxy \\
\hline OPP: 15 & ER: 85 & $15 \%$ OPP/ Epoxy \\
\hline OPP: 20 & ER: 80 & $20 \%$ OPP/ Epoxy \\
\hline OPP: 25 & ER: 75 & $25 \%$ OPP/Epoxy \\
\hline OPP: 30 & ER: 70 & $30 \%$ OPP/ Epoxy \\
\hline OPP: 35 & ER: 65 & $35 \%$ OPP/ Epoxy \\
\hline
\end{tabular}

\subsection{Water absorption test and diffusivity measurement}

Three samples of pure epoxy and its fabricated composites were cut into a pre-defined shape and size for the water absorption test and were numbered accordingly. In water absorption standards in the literature, it is required to replicate measurements at least three times during experiments to reduce errors and consequently wrong interpretation of results. Consistent with this norm, this article follows the best standard practices of repeating the experiments three times and the average values are used for further analysis. As a result, we have $\mathrm{A} 1(0)-\mathrm{A} 3(0)$ for the pure epoxy samples, $\mathrm{A} 1(5)-\mathrm{A} 3(5)$, $\mathrm{A} 1(10)-\mathrm{A} 3(10), \mathrm{A} 1(15)-\mathrm{A} 3(15), \mathrm{A} 1(20)-\mathrm{A} 3(20), \mathrm{A} 1(25)-\mathrm{A} 3(25), \mathrm{A} 1(30)-\mathrm{A} 3(30), \mathrm{A} 1(35)-\mathrm{A} 3(35)$ for the $5,10,15,20,25,30$ and $35 \% \mathrm{OPP} /$ Epoxy composites, respectively. The average results obtained from each set of samples is used to ensure a balance of measurements. The water absorption and diffusivity of the neat epoxy and its composites were measured over three days and seven days period using Equations (1) and (2) as presented in Table 2. While the literature has addressed middle range time of experiments such as 72 days, which was declared in the water absorption experiments by Ayanladun and Oke (2020), it was thought that the aspect of a short term such as three and seven days' experiments on agro waste-reinforced composites will fill a gap in the literature and therefore pursued in this article. Furthermore, the water absorption of the composites showed the capacity of the samples to absorb water, while the diffusivity showed that the water absorption behaviour to be Fickian.

$$
\begin{aligned}
& W_{a}(\%)=\left(\frac{M_{t}-M_{i}}{M_{i}}\right) \times 100 \\
& \frac{M_{t}}{M_{o}}=\frac{4}{L}\left[\frac{D}{\pi}\right]^{0.5} t^{0.5}
\end{aligned}
$$

where $M_{t}$ denotes the mass of the sample at a given time $t, M_{o}$ is the initial mass of the sample, $L$ stands for the sample's thickness, while $D$ is the diffusivity or diffusion coefficient of the sample 
Table 2. Water absorption and diffusivity of pure epoxy and its composites

\begin{tabular}{|c|c|c|c|c|c|}
\hline \multirow{2}{*}{ Sample label } & \multirow{2}{*}{$\begin{array}{c}\text { OPPs content } \\
(\%)\end{array}$} & \multicolumn{2}{|c|}{ Three days } & \multicolumn{2}{|c|}{ Seven days } \\
\cline { 3 - 6 } & & $\mathrm{W}_{\mathrm{a}}$ & $\begin{array}{c}\mathrm{D} \times 10^{-10} \\
\left(\mathrm{~m}^{2} / \mathrm{sec}\right)\end{array}$ & $\begin{array}{c}\mathrm{W}_{\mathrm{a}} \\
(\%)\end{array}$ & $\begin{array}{c}\mathrm{D} \times 10^{-10} \\
\left(\mathrm{~m}^{2} / \mathrm{sec}\right)\end{array}$ \\
\hline $\mathrm{A} 1(0)-\mathrm{A} 3(0)$ & 0 & 1.91 & 3.75 & 2.16 & 1.59 \\
\hline $\mathrm{A} 1(5)-\mathrm{A} 3(5)$ & 5 & 5.63 & 4.29 & 6.88 & 1.88 \\
\hline $\mathrm{A} 1(10)-\mathrm{A} 3(10)$ & 10 & 7.64 & 4.42 & 8.83 & 1.94 \\
\hline $\mathrm{A} 1(15)-\mathrm{A} 3(15)$ & 15 & 9.48 & 4.71 & 11.92 & 2.22 \\
\hline $\mathrm{A} 1(20)-\mathrm{A} 3(20)$ & 20 & 12.95 & 5.29 & 19.59 & 3.32 \\
\hline $\mathrm{A} 1(25)-\mathrm{A} 3(25)$ & 25 & 15.61 & 5.85 & 31.03 & 3.21 \\
\hline $\mathrm{A} 1(30)-\mathrm{A} 3(30)$ & 30 & 17.06 & 5.83 & 27.16 & 3.9 \\
\hline $\mathrm{A} 1(35)-\mathrm{A} 3(35)$ & 35 & 19.69 & 6.01 & 33.99 & 3.25 \\
\hline
\end{tabular}

\subsection{Optimization of diffusivity}

To minimise the diffusivity of water molecules and reduce water uptake into the composite, an optimal setting of the diffusivity parameters obtained through optimization. Taguchi method of optimization uses a statistical system called signal-to-noise $(\mathrm{S} / \mathrm{N})$ ratio to evaluate the performance of experimental processes. This is done using an orthogonal array of evenly distributed factors and levels. Factors are the parameters involved in the experimental process, while levels describe the conditions of the factors during the process. Taguchi method uses three main quality characteristics for optimising an experimental process. These are the "lower-the-better" (LB), the "higher-the-better" (HB) and "nominal-the-best" (NB) quality characteristics. Minimum diffusivity of water molecules is desired to reduce water uptake by the composites, therefore, the LB quality characteristics adapted from Zareh et al. (2013) was used in this investigation according to Equation (3) which is described as follows:

$\mathrm{S} / \mathrm{N}=-10 \log \frac{1}{n} \sum^{n} y_{i}^{2}$

where $n$ is the of vatues at a trial condition and $y_{\mathrm{i}}$ is each observed value.

Another aspect of optimization carried out in this investigation is by combining the Taguchi method with the Pareto 80-20 rule to obtain the Taguchi-Pareto method. This was done by arranging the factor levels in ascending order from the least to the highest value. The total sum of the factors was calculated, while the percentage contribution of each factor level was obtained. Further, the cumulative percentage contribution of each factor level is derived from the total sum. At $80 \%$ cumulative percentage, the Pareto 80-20 rule is applied. The factor levels below the $80 \%$ limit are cut off and termed insignificant to optimality. The factor levels above the $80 \%$ limit are used to form a revised table of factors and levels. This leaves us with a 2 factor, 4 level optimization problem, which can be solved using an $\mathrm{L}_{8} 4^{2}$ orthogonal array from Minitab 16. 


\section{Results and Discussion}

\subsection{Taguchi optimization}

The data collected for the diffusivity parameters from the water absorption experiment are described in Table 3.

Table 3. Diffusivity parameters from the water absorption experiment

\begin{tabular}{|c|c|c|c|c|c|c|}
\hline \multirow{2}{*}{ Sample label } & \multicolumn{3}{|c|}{3 days } & \multicolumn{3}{c|}{7 days } \\
\cline { 2 - 7 } & $\begin{array}{c}\text { Initial } \\
\mathrm{wt}(\mathrm{g})\end{array}$ & $\begin{array}{c}\text { Final } \\
\mathrm{wt}(\mathrm{g})\end{array}$ & $\begin{array}{c}\text { Thickness } \\
(\mathrm{m})\end{array}$ & $\begin{array}{c}\text { Initial } \\
\mathrm{wt}(\mathrm{g})\end{array}$ & $\begin{array}{c}\text { Final } \\
\mathrm{wt}(\mathrm{g})\end{array}$ & $\begin{array}{c}\text { Thickness } \\
(\mathrm{m})\end{array}$ \\
\hline $\mathrm{A} 1(0)-\mathrm{A} 3(0)$ & 26.32 & 26.82 & 0.0218 & 26.32 & 26.89 & 0.0217 \\
\hline $\mathrm{A} 1(5)-\mathrm{A} 3(5)$ & 23.55 & 24.88 & 0.023 & 23.55 & 25.17 & 0.0225 \\
\hline $\mathrm{A} 1(10)-\mathrm{A} 3(10)$ & 23.09 & 24.72 & 0.0224 & 23.09 & 25.01 & 0.0225 \\
\hline $\mathrm{A} 1(15)-\mathrm{A} 3(15)$ & 15.13 & 14.49 & 0.0228 & 15.13 & 16.8 & 0.0234 \\
\hline $\mathrm{A} 1(20)-\mathrm{A} 3(20)$ & 17.48 & 19.66 & 0.0234 & 17.48 & 20.76 & 0.0267 \\
\hline $\mathrm{A} 1(25)-\mathrm{A} 3(25)$ & 8.47 & 9.73 & 0.024 & 8.47 & 10.97 & 0.0239 \\
\hline $\mathrm{A} 1(30)-\mathrm{A} 3(30)$ & 11.97 & 13.99 & 0.0237 & 11.97 & 15.19 & 0.0269 \\
\hline $\mathrm{A} 1(35)-\mathrm{A} 3(35)$ & 11.4 & 13.47 & 0.0236 & 11.4 & 14.88 & 0.0237 \\
\hline
\end{tabular}

The collected data values are bifurcated using the arithmetic mean and organized into three factors and four levels. This gives a three-factor, four-level optimization problem described in Table 4. The commercial statistical software Minitab 16 was used to generate an $\mathrm{L}_{16} 3^{4}$ orthogonal array. Table 5 shows the $\mathrm{L}_{16} 3^{4}$ orthogonal array with sixteen experimental trials performed to determine the effect of each factor and find their optimal combination.

Table 4. Factors and their levels

\begin{tabular}{|l|c|c|c|c|c|c|c|c|}
\hline \multirow{2}{*}{ Parameters } & \multicolumn{4}{|c|}{ Three days } & \multicolumn{4}{c|}{ Seven days } \\
\cline { 2 - 9 } & Level 1 & Level 2 & Level 3 & Level 4 & Level 1 & Level 2 & Level 3 & Level 4 \\
\hline P: Initial wt (g) & 24.94 & 19.11 & 12.97 & 11.69 & 24.94 & 19.11 & 12.97 & 11.69 \\
\hline Q: Final wt (g) & 25.85 & 19.61 & 14.69 & 13.73 & 26.03 & 20.91 & 15.87 & 15.04 \\
\hline R: Thickness (m) & 0.0224 & 0.0226 & 0.0237 & 0.02365 & 0.0221 & 0.0226 & 0.0253 & 0.0253 \\
\hline
\end{tabular}

Table 5. $\mathrm{L}_{16} 3^{4}$ orthogonal array

\begin{tabular}{|c|c|c|c|c|c|c|c|}
\hline S/No & $\mathrm{P}$ & $\mathrm{Q}$ & $\mathrm{R}$ & $\mathrm{S} /$ No & $\mathrm{P}$ & $\mathrm{Q}$ & $\mathrm{R}$ \\
\hline 1 & 1 & 1 & 1 & 9 & 3 & 1 & 3 \\
\hline 2 & 1 & 2 & 2 & 10 & 3 & 2 & 4 \\
\hline 3 & 1 & 3 & 3 & 11 & 3 & 3 & 1 \\
\hline 4 & 1 & 4 & 4 & 12 & 3 & 4 & 2 \\
\hline 5 & 2 & 1 & 2 & 13 & 4 & 1 & 4 \\
\hline 6 & 2 & 2 & 1 & 14 & 4 & 2 & 3 \\
\hline 7 & 2 & 3 & 4 & 15 & 4 & 3 & 2 \\
\hline 8 & 2 & 4 & 3 & 16 & 4 & 4 & 1 \\
\hline
\end{tabular}

Taguchi optimization was carried out on the factors and levels for the three days and seven days diffusivity parameters using Equation (2) for the LB quality characteristics. The experimental results and the obtained $\mathrm{S} / \mathrm{N}$ ratios are shown in Tables 6 and 7 for the three days and seven days diffusivity respectively. 
Table 6. Taguchi experimental results for three days diffusivity parameters

\begin{tabular}{|c|c|c|c|c|}
\hline S/No & $\mathrm{P}$ & $\mathrm{Q}$ & $\mathrm{R}$ & $\mathrm{S} / \mathrm{N}$ ratio \\
\hline 1 & 24.94 & 25.85 & 0.0224 & -26.335447 \\
\hline 2 & 24.94 & 19.61 & 0.0226 & -25.257168 \\
\hline 3 & 24.94 & 14.69 & 0.0237 & -24.460192 \\
\hline 4 & 24.94 & 13.73 & 0.0236 & -24.316409 \\
\hline 5 & 19.11 & 25.85 & 0.0237 & -25.371536 \\
\hline 6 & 19.11 & 19.61 & 0.02365 & -23.977922 \\
\hline 7 & 19.11 & 14.69 & 0.0224 & -22.870464 \\
\hline 8 & 19.11 & 13.73 & 0.0226 & -22.661576 \\
\hline 9 & 12.97 & 25.85 & 0.02365 & -24.453156 \\
\hline 10 & 12.97 & 19.61 & 0.0237 & -22.654260 \\
\hline 11 & 12.97 & 14.69 & 0.0226 & -21.072298 \\
\hline 12 & 12.97 & 13.73 & 0.0224 & -20.752236 \\
\hline 13 & 11.69 & 25.85 & 0.0226 & -24.286094 \\
\hline 14 & 11.69 & 19.61 & 0.0224 & -22.398904 \\
\hline 15 & 11.69 & 14.69 & 0.02365 & -20.699797 \\
\hline 16 & 11.69 & 13.73 & 0.0237 & -20.349886 \\
\hline
\end{tabular}

Table 7. Taguchi experimental results for seven days of diffusivity parameters

\begin{tabular}{|c|c|c|c|c|}
\hline $\mathrm{S} / \mathrm{No}$ & $\mathrm{P}$ & $\mathrm{Q}$ & $\mathrm{R}$ & $\mathrm{S} / \mathrm{N}$ ratio \\
\hline 1 & 24.94 & 26.03 & 0.0221 & -26.366767 \\
\hline 2 & 24.94 & 20.91 & 0.0229 & -25.478699 \\
\hline 3 & 24.94 & 15.87 & 0.0253 & -24.643212 \\
\hline 4 & 24.94 & 15.04 & 0.0253 & -24.513800 \\
\hline 5 & 19.11 & 26.03 & 0.0229 & -25.410604 \\
\hline 6 & 19.11 & 20.91 & 0.0221 & -24.272809 \\
\hline 7 & 19.11 & 15.87 & 0.0253 & -23.131988 \\
\hline 8 & 19.11 & 15.04 & 0.0253 & -22.947559 \\
\hline 9 & 12.97 & 26.03 & 0.0253 & -24.501374 \\
\hline 10 & 12.97 & 20.91 & 0.0253 & -23.049568 \\
\hline 11 & 12.97 & 15.87 & 0.0221 & -21.462090 \\
\hline 12 & 12.97 & 15.04 & 0.0229 & -21.188410 \\
\hline 13 & 11.69 & 26.03 & 0.0253 & -24.336193 \\
\hline 14 & 11.69 & 20.91 & 0.0253 & -22.817035 \\
\hline 15 & 11.69 & 15.87 & 0.0229 & -21.122849 \\
\hline 16 & 11.69 & 15.04 & 0.0221 & -20.826157 \\
\hline
\end{tabular}

The $\mathrm{S} / \mathrm{N}$ ratios are grouped into $\mathrm{S} / \mathrm{N}$ response tables according to the factor level distribution in the orthogonal array. This is done by arranging the $\mathrm{S} / \mathrm{N}$ ratios firstly by factor level for each column in the orthogonal array and to find their respective arithmetic means. For example, in the first column of the orthogonal array, experimental trials 1, 2, 3 and 4 were the runs at which factor $\mathrm{P}$ is set at level 1 . The related $\mathrm{S} / \mathrm{N}$ ratios for $\mathrm{P}_{1}$, are those experimental trials $\mathrm{S} / \mathrm{N}$ ratios. Therefore, their average is the $\mathrm{S} / \mathrm{N}$ response for $\mathrm{P}_{1}$ :

$\mathrm{P}_{1}=1 / 3(-26.335447+-25.257168+-24.460192+-24.316409)=-25.0923041$

while $\mathrm{P}_{2}=-23.72037, \mathrm{P}_{3}=22.232987$ and $\mathrm{P}_{4}=-21.93367$ 
Notwithstanding the type of quality characteristics used, it is suggested that a higher $\mathrm{S} / \mathrm{N}$ ratio indicates a better quality characteristic. This means the optimal level of the process parameters is the level with the highest $\mathrm{S} / \mathrm{N}$ ratio. Consequently, the optimal parametric setting for the three days diffusivity is obtained as $\mathrm{P}_{4} \mathrm{Q}_{4} \mathrm{R}_{1}$ (Table 8). This translates to $11.69 \mathrm{~g}$ initial weight, $13.73 \mathrm{~g}$ final weight and a thickness of $0.0224 \mathrm{~m}$ as the optimal setting that gives the minimal diffusivity of water into the OPPs/Epoxy composites over the three days.

Table 8. S/N Response table for optimization of diffusivity parameters

\begin{tabular}{|c|c|c|c|c|c|c|}
\hline \multirow{2}{*}{ Levels } & \multicolumn{3}{|c|}{ Three days } & \multicolumn{3}{c|}{ Seven days } \\
\cline { 2 - 7 } & $\mathrm{P}$ & $\mathrm{Q}$ & $\mathrm{R}$ & $\mathrm{P}$ & $\mathrm{Q}$ & $\mathrm{R}$ \\
\hline 1 & -25.0923 & -25.1116 & -22.9339 & -25.2506 & -25.1537 & -23.2319 \\
\hline 2 & -23.7204 & -23.5721 & -23.0202 & -23.9407 & -23.9045 & -23.3001 \\
\hline 3 & -22.2330 & -22.2757 & -23.4935 & -22.5504 & -22.5900 & -23.7273 \\
\hline 4 & -21.9337 & -22.0200 & -23.5318 & -22.2756 & -22.3689 & -23.7578 \\
\hline
\end{tabular}

In the same vein, an optimal setting of $\mathrm{P}_{4} \mathrm{Q}_{4} \mathrm{R}_{1}$ was obtained for the seven days of diffusivity parameters. This can be read as $11.69 \mathrm{~g}$ initial weight, $15.04 \mathrm{~g}$ final weight and a thickness of 0.0221 $\mathrm{m}$ which will ensure the lowest diffusivity of water into the OPPs/Epoxy composites through the seven days. The selection of lowest initial and final weights by the Taguchi method indicate that at the end of the respective diffusivity periods, the new initial and final weights as a result of diffusivity would still maintain the dimensional stability of the composites. In like manner, the least amount of thickness has been selected to allow for minimal diffusivity and water uptake of water into the composites. Hence, these dimensions and specifications can be considered by composite engineers and manufacturers when considering minimal uptake of water as a basis of design in composite manufacture as indicated in the main effects diagrams (Figures 2 and 3).
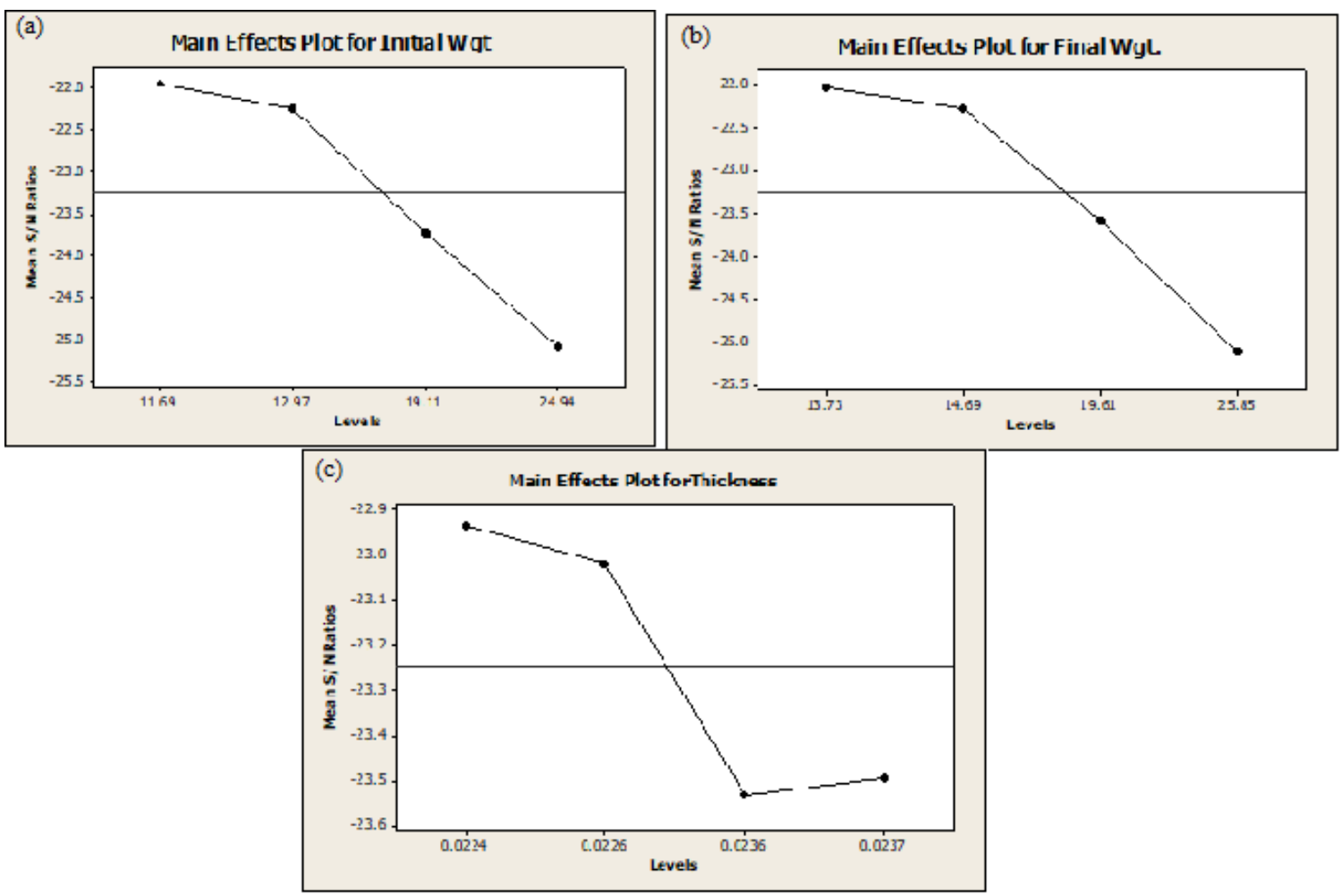

Figure 2. Main Effect Plots for Three days (a) Initial weight, (b) Final Weight, and (c) Thickness 

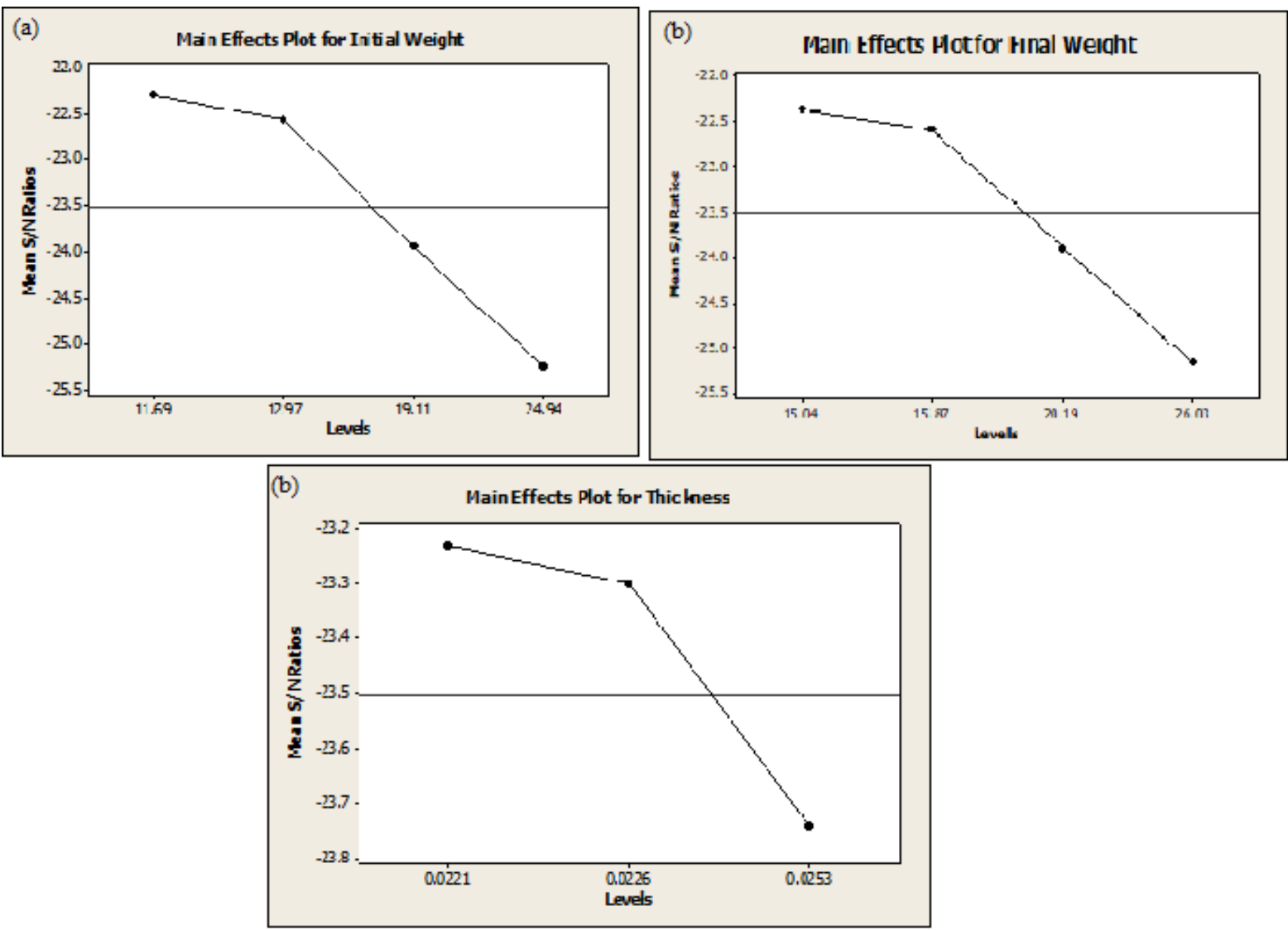

Figure 3. Main Effect Plots for Seven days (a) Initial weight, (b) Final Weight, and (c) Thickness

\subsection{Taguchi-Pareto optimization method}

The application of the Taguchi-Pareto method produces a revised table of factors and levels for the three days and seven days of diffusivity parameters. This shows that the thickness parameter $(R)$ had the least contribution to optimality, as a result, is not present in the revised table of factors and levels. Also, factor levels $P_{3}$ and $P_{4}$ for the three days and seven days were not included in the revised table of factors and levels because their contribution to optimality was insignificant (Table 9).

Table 9. Factors and their levels

\begin{tabular}{|c|c|c|c|c|c|c|c|c|}
\hline \multirow{2}{*}{ Parameters } & \multicolumn{4}{|c|}{ Three days } & \multicolumn{4}{c|}{ Seven days } \\
\cline { 2 - 9 } & Level 1 & Level 2 & Level 3 & Level 4 & Level 1 & Level 2 & Level 3 & Level 4 \\
\hline P: Initial wt (g) & 24.94 & 19.11 & - & - & 24.94 & 19.11 & - & - \\
\hline Q: Final wt (g) & 25.85 & 19.61 & 14.69 & 13.73 & 26.03 & 20.91 & 15.87 & 15.04 \\
\hline
\end{tabular}

From Table 10, there is a 2 factor, 4 level optimization problem, which can be solved by generating an $\mathrm{L}_{16}$ orthogonal array from Minitab 16 described by Table 10 . 
Table 10. $\mathrm{L}_{16} 2^{4}$ Orthogonal array

\begin{tabular}{|c|c|c|}
\hline $\mathrm{S} / \mathrm{No}_{0}$ & $\mathrm{P}$ & $\mathrm{Q}$ \\
\hline 1 & 1 & 1 \\
\hline 2 & 1 & 2 \\
\hline 3 & 1 & 3 \\
\hline 4 & 1 & 4 \\
\hline 5 & 2 & 1 \\
\hline 6 & 2 & 2 \\
\hline 7 & 2 & 3 \\
\hline 8 & 2 & 4 \\
\hline 9 & 3 & 1 \\
\hline 10 & 3 & 2 \\
\hline 11 & 3 & 3 \\
\hline 12 & 3 & 4 \\
\hline 13 & 4 & 1 \\
\hline 14 & 4 & 2 \\
\hline 15 & 4 & 3 \\
\hline 16 & 4 & 4 \\
\hline
\end{tabular}

Table 11. Taguchi-Pareto experimental results for three days and seven days parameters

\begin{tabular}{|c|c|c|c|c|c|c|}
\hline \multirow{2}{*}{ S/No } & \multicolumn{3}{|c|}{ Three days } & \multicolumn{3}{c|}{ Seven days } \\
\cline { 2 - 7 } & $\mathrm{P}$ & $\mathrm{Q}$ & $\mathrm{S} /$ No & $\mathrm{P}$ & $\mathrm{Q}$ & $\mathrm{S} / \mathrm{No}$ \\
\hline 1 & 24.94 & 25.85 & -18.409601 & 24.94 & 26.03 & -26.366766 \\
\hline 2 & 24.94 & 19.61 & -27.018078 & 24.94 & 20.91 & -25.478697 \\
\hline 3 & 24.94 & 14.69 & -26.221102 & 24.94 & 15.87 & -24.643209 \\
\hline 4 & 24.94 & 13.73 & -26.077319 & 24.94 & 15.04 & -24.513797 \\
\hline 5 & 19.11 & 25.85 & -27.132446 & 19.11 & 26.03 & -25.410602 \\
\hline 6 & 19.11 & 19.61 & -25.738831 & 19.11 & 20.91 & -24.272806 \\
\hline 7 & 19.11 & 14.69 & -24.631373 & 19.11 & 15.87 & -23.131984 \\
\hline 8 & 19.11 & 13.73 & -24.422484 & 19.11 & 15.04 & -22.947554 \\
\hline 9 & - & 25.85 & -25.238911 & - & 26.03 & -23.538271 \\
\hline 10 & - & 19.61 & -22.839252 & - & 20.91 & -21.635868 \\
\hline 11 & - & 14.69 & -20.330136 & - & 15.87 & -19.240326 \\
\hline 12 & - & 13.73 & -19.743111 & - & 15.04 & -18.773744 \\
\hline 13 & - & 25.85 & -25.238911 & - & 26.03 & -23.538271 \\
\hline 14 & - & 19.61 & -22.839252 & - & 20.91 & -21.635868 \\
\hline 15 & - & 14.69 & -20.330136 & - & 15.87 & -19.240326 \\
\hline 16 & - & 13.73 & -19.743111 & - & 15.04 & -18.773744 \\
\hline
\end{tabular}

Table 12. S/No response table

\begin{tabular}{|c|c|c|c|c|}
\hline \multirow{2}{*}{ S/No } & \multicolumn{2}{|c|}{ Three days } & \multicolumn{2}{c|}{ Seven days } \\
\cline { 2 - 5 } & $\mathrm{P}$ & $\mathrm{Q}$ & $\mathrm{P}$ & $\mathrm{Q}$ \\
\hline 1 & -24.4315 & -24.0049 & -27.6836 & -27.6496 \\
\hline 2 & -25.4813 & -24.6089 & -26.3394 & -26.6366 \\
\hline 3 & - & -22.8782 & - & -25.6485 \\
\hline 4 & - & -22.4966 & - & -25.4916 \\
\hline
\end{tabular}


The Taguchi-Pareto method obtained an optimal parameter setting of $P_{1} Q_{4}$ for the 3 days (Table 11 ) and $P_{2} Q_{4}$ for the seven days diffusivity parameters (Table 12). This can be read as $24.94 \mathrm{~g}$ and $13.73 \mathrm{~g}$ for three days measurements as well as $19.11 \mathrm{~g}$ and $15.04 \mathrm{~g}$ for the seven days respectively.

\subsection{Analysis of variance (ANOVA)}

The experimental trials carried out by the Taguchi method makes available information useful for choosing an optimal set of parameters for estimating the relative significance of each factor for further investigations. The analysis of variance (ANOVA) method is used to measure the effect of diffusivity parameters on the quality characteristic. This is done by separating the general variations from the mean $\mathrm{S} / \mathrm{N}$ ratio into individual contributions by the parameter and the error. The total sum of squares from the total mean $\mathrm{S} / \mathrm{N}$ ratio can be calculated using Equation (3) developed by Zareh but used in [9]

$$
S S_{T}=\sum_{j=1}^{n}(S / N)_{j}^{2}-\frac{1}{n}\left[\sum_{j=1}^{n}(S / N)_{j}\right]^{2}
$$

where $\mathrm{n}$ is the number of experiments in the orthogonal array and $(\mathrm{S} / \mathrm{N})_{\mathrm{j}}$ is the $\mathrm{S} / \mathrm{N}$ ratio of the jth experiment. The sum of squares due to deviation from the total mean $\mathrm{S} / \mathrm{N}$ ratio for parameter $A$ is given from Equation (4) developed by Zareh but used in [9] as

$$
S S_{A}=\sum_{i=1}^{m} \frac{\left[(S / N)_{i}\right]^{2}}{p}-\frac{1}{n}\left[\sum_{j=1}^{n}(S / N)_{j}\right]^{2}
$$

where $\mathrm{m}$ is the number of parameter levels ( $l=4$ in this investigation), $i$ is the level number of this specific parameter $a,(S / N)_{i}$ is the addition of the $S / N$ ratio about

this parameter $a$ and level $i$, while $p$ is the repetition of each level of parameter $a$. the percentage contribution of the $a^{\text {th }}$ parameter can be obtained using Equation (5) developed by Zareh but used in [9] as follows

$$
P_{A}(\%)=\frac{S S_{A}}{S S_{T}} \times 100
$$

The ANOVA results obtained for the three days and seven days diffusivity parameters are presented in Tables 9 and 10, respectively. From Table 9, the initial weight (parameter $P$ ) is seen to be the most influential factor with a percentage contribution of $49.89 \%$, closely followed by the final weight with a percentage contribution of $47.17 \%$. Thickness has the least influence on the diffusivity and is termed insignificant and grouped as an error. Table 10 describes the ANOVA results for the seven days of diffusivity parameters. Again, the initial weight $(51.58 \%)$ and final weight $(45.65 \%)$ have the highest contribution to the diffusivity of the OPPs/Epoxy composites. thickness maintains the least contribution is termed as insignificant and as an error. In the analysis of variance used to evaluate parameters, the interest is to know the composition of the variance by values (Tables 13 and 14) and this forms the basis to determine the cut off points for the Pareto aspect of the Taguchi-Pareto Scheme. The results of this article compare favourably with the existing literature as reported in Ajibade et al. [9] that implemented the Taguchi-Pareto scheme for composite development activity. 
Table 13. Analysis of variance table for three days diffusivity parameters

\begin{tabular}{|c|c|r|r|c|}
\hline Factors & $\begin{array}{c}\text { Degree of } \\
\text { freedom }\end{array}$ & $\begin{array}{c}\text { Sum of } \\
\text { square }\end{array}$ & $\begin{array}{c}\text { Mean } \\
\text { square }\end{array}$ & $\begin{array}{c}\text { Percentage } \\
\text { contribution (\%) }\end{array}$ \\
\hline $\mathrm{P}$ & 3 & 25.53128 & 12.7656 & 49.898 \\
\hline $\mathrm{Q}$ & 3 & 24.13727 & 12.0686 & 47.1736 \\
\hline $\mathrm{R}$ & 3 & 1.17714 & 0.5886 & 2.3005 \\
\hline Error & & & & 100 \\
\hline Total & & 51.1669 & 25.42285 & 0.6277 \\
\hline (Error) & & 0.3212 & 0.1606 & \\
\hline
\end{tabular}

Table 14. Analysis of variance table for seven days diffusivity parameters

\begin{tabular}{|c|c|r|r|r|}
\hline Factors & $\begin{array}{c}\text { Degree of } \\
\text { freedom }\end{array}$ & $\begin{array}{c}\text { Sum of } \\
\text { square }\end{array}$ & $\begin{array}{c}\text { Mean } \\
\text { square }\end{array}$ & \multicolumn{1}{c|}{$\begin{array}{c}\text { Percentage } \\
\text { contribution (\%) }\end{array}$} \\
\hline $\mathrm{P}$ & 3 & 22.60675 & 11.3034 & 51.5848 \\
\hline $\mathrm{Q}$ & 3 & 20.0073 & 10.0037 & 45.6535 \\
\hline $\mathrm{R}$ & 3 & 0.9050 & 0.4525 & 2.0651 \\
\hline Error & & & & 100 \\
\hline Total & & 43.8244 & 21.7596 & 0.6965 \\
\hline (Error) & & 0.3053 & 0.1526 &
\end{tabular}

\subsection{Summary of results}

The summary of results obtained from this study is as follows:

- An optimal parametric setting of $P_{4} Q_{4} R_{I}$ was obtained for the three days of diffusivity parameters. This can be interpreted as $11.69 \mathrm{~g}, 13.73 \mathrm{~g}$ and $0.0224 \mathrm{~m}$ for the initial weight, final weight and thickness of the composites respectively.

- An optimal parametric setting of $P_{4} Q_{4} R_{I}$ was obtained for the seven days of diffusivity parameters. This can be read as $11.69 \mathrm{~g}, 15.04 \mathrm{~g}$ and $0.0221 \mathrm{~m}$ for the initial weight, final weight and thickness of the composites respectively.

- The ANOVA results indicate clearly that the initial weight of the composite is the most important factor in the diffusivity of the composites, closely followed by the final weight. The results also highlight the less significant role the thickness parameter plays in the optimization of diffusivity of water into the composites. Overall, the ANOVA results show that as the diffusivity of the composite is reduced, the degree of importance of these parameters increases significantly.

- An optimal parametric setting of $P_{1} Q_{4}$ was obtained for the three days of diffusivity parameters. This can be read as $24.94 \mathrm{~g}, 13.73 \mathrm{~g}$ for the initial and final weights of the composites respectively.

- The optimal parametric setting for the seven days diffusivity parameters was obtained as $P_{2} Q_{4}$. This can be interpreted as $19.11 \mathrm{~g}$ and $15.04 \mathrm{~g}$ for the initial and final weights of the composites respectively.

\section{Conclusions}

This article has proposed two quantitative tools to evaluate the diffusivity of an orange peel based composite and optimize the parameters using the Taguchi Scheme and the Taguchi-Pareto method. This novel attempt lowers the diffusion of water and ultimately reduces the water uptake of composites, hereby maintaining dimensional accuracy and prolonging the life span of composites. The 
optimization of diffusivity parameters was carried out according to two different periods of measurements namely, three days and seven days' diffusivity parameters. The proposed framework uses orthogonal arrays for the Taguchi method and a combination of orthogonal arrays, analysis of variance and Pareto principle for the Taguchi-Pareto method. These tools gathered information to develop the optimal parametric settings in the non-prioritized and prioritized forms of the parameters.

The conclusion from the study is that both the Taguchi Scheme and the Taguchi-Pareto schemes are feasible in analysis during the quantitative analysis of the orange peel composite. Compared with the sub-optimal evaluation method that is primarily determining the values of parameters traditionally, the Taguchi method and Taguchi-Pareto method were found to be competent in dealing with the suboptimal issues in parametric determination and the evaluation of prioritized parameters in responses concerning diffusivity of orange peel composite for the optimal solution in contrast with sub-optimal solutions. This offers important details regarding the projected enhancement in the quantified amount of the system responses. Consequently, the two methods proposed offer valuable assistance to composite development engineers and designers to achieve optimal and prioritized parametric values in the diffusivity experiments for the development of orange peel composites. From the practical viewpoint, the experimental analysis allows deriving some essential insights into the optimization problem. The experimental analysis confirms that the optimal parametric setting, the analysis of variance and Pareto results are critical aspects in the Taguchi Scheme and Taguchi-Pareto method. The optimal settings obtained by the Taguchi-Pareto leaves out the thickness parameter because it is not significant to optimality. This correlates with the results by ANOVA which showed that the thickness parameter is of less significance and termed as an error. Given the experience gained in the experiments and literature review, some aspects require future studies. A key aspect is modelling the behaviour of the levels for each factor. At present, the experience of the operator is used. However, in reality, it may be modelled according to a stochastic model or some other mathematical and statistical distribution.

\section{Acknowledgement}

The authors thank Mr. Salami of the Soil laboratory, University of Lagos, Lagos, Nigeria, for the assistance offered to them in the course of the experiment

\section{References}

[1] Chen, R. S., Muhammad, Y. H., \& Ahmad, S. (2021). Physical, mechanical and environmental stress cracking characteristics of epoxy/glass fiber composites: Effect of matrix/fiber modification and fiber loading. Polymer Testing, 96, 107088. https://doi.org/10.1016/j.polymertesting.2021.107088

[2] Deng, Y., Li, W., Ma, J., \& Li, Y. (2021). Thermal-mechanical-oxidation coupled first matrix cracking stress model for fiber reinforced ceramic-matrix composites. Journal of the European Ceramic Society, 41(7), 4016-4024. https://doi.org/10.1016/j.jeurceramsoc.2021.02.033

[3] Fudger, S., Sediako, D., Karandikar, P., \& Ni, C. (2017). Residual stress induced mechanical property enhancement in steel encapsulated light metal matrix composites. Materials Science and Engineering: A, 699, 10-17. https://doi.org/10.1016/j.msea.2017.05.073

[4] Chowdhury, A. F., Mari, D., \& Schaller, R. (2009). Analysis of transient mechanical loss due to thermal stresses in metal matrix composites. Materials Science and Engineering: A, 521, 310-313.. https://doi.org/10.1016/j.msea.2008.09.085

[5] Ghasemi, A. R., Mohammadi, M. M., \& Mohandes, M. (2015). The role of carbon nanofibers on thermomechanical properties of polymer matrix composites and their effect on reduction of residual $\begin{array}{llll}\text { stresses. Composites } & \text { Part } & \text { B } & \text { Engineering, 77, }\end{array}$ https://doi.org/10.1016/j.compositesb.2015.03.065

[6] Gupta, A., Joshi, A., Tejyan, S., Gangil, B., \& Singh, T. (2020). Comparative study of mechanical 
properties of orange peel filled epoxy composites joined by a mechanical fastener. Materials Today: Proceedings. https://doi.org/10.1016/j.matpr.2020.11.020

[7] Awasthi, A., \& Saxena, K. K. (2019). Evaluation of Mechanical Properties of Orange Peel Reinforced Epoxy Composite. Materials Today: $\quad$ Proceedings, $18, \quad$ 3821-3826. https://doi.org/10.1016/j.matpr.2019.07.320

[8] Ajibade O.A., Agunsoye J.O. \& Oke S.A. (2016). Tapped density optimization for four agricultural wastes: Part II - Performance analysis, main effects of process parameters and Taguchi-Pareto, Acta Periodica Technologica, 47, 129-142. DOI:10.2298/APT1647129A

[9] Ajibade O.A., Agunsoye J.O. \& Oke S.A. (2019). Optimization of water absorption parameters of dualfiller filled composites using Taguchi and moderated Taguchi techniques, Kufa Journal of Engineering, 10(2), 134-151.

[10] Okanminiwei L. \& Oke S.A., (2020). Optimization of maintenance downtime for handling equipment in a container terminal using Taguchi scheme, Taguchi-Pareto method and Taguchi-ABC method, Indonesian Journal of Industrial Engineering \& Management, 1(2), 69-90.

[11] Oji, B.C. \& Oke, S.A. (2020). Optimization of bottling process using "hard" total quality management elements, The TQM Journal, Vol. 33 No. 2, pp. 473-502. https://doi.org/10.1108/TQM-03-2020-0057

[12] Obradović T., Vlačić B. \& Dabića M. (2021). Open innovation in the manufacturing industry: A review and research agenda, Technovation, $102, \quad$ Article 102221. https://doi.org/10.1016/j.technovation.2021.102221

[13] Tasnim, S., Shaikh, F. U. A., \& Sarker, P. K. (2021). Mechanical properties and microstructure of lightweight polymer composites containing mono and hybrid fillers sourced from recycled solid $\begin{array}{llll}\text { wastes. Construction } & \text { and } & \text { Building } & \text { Materials, 277, }\end{array}$ https://doi.org/10.1016/j.conbuildmat.2021.122369

[14] Anoopisan, Barath L. \& Nagakalyan S. (2015). Interfacial behaviour of composites of polymer and orange peel particulates, International Journal on Theoretical and Applied Research in Mechanical Engineering, 4 (4), 27-33. ISSN: 2319-3182

[15] Ojha S., Raghavendra G., Acharya S.K., Kumar P. (2012). Fabrication and study of mechanical properties of orange peel reinforced polymer composite, Caspian Journal of Applied Sciences Research, 1(13), 190194.

[16] Victor, A., Atuanya, C. U., Igogori, E. A., \& Ihom, P. (2013). Development of high-density polyethylene/orange peels particulate bio-composite. Gazi University Journal of Science, 26(1), 107-117. e-ISSN 2147-1762

[17] Aigbodion, V. S., Hassan, S. B., \& Atuanya, C. U. (2012). Kinetics of isothermal degradation studies by thermogravimetric data: effect of orange peels ash on thermal properties of high density polyethylene (HDPE). Journal Material Environment Science, 3(6), 1027-36. ISSN : 2028-2508

[18] Praveenkumar K. \& Nagaraj C. (2016). An investigation on mechanical characterization of orange peel reinforced epoxy composite, IOSR Journal of Mechanical and Civil Engineering, 33-41.e-ISSN 22781684

[19] Karthikayan S., Balakumaran A., Abilesh R., Buraneshwaran S., Jeeva P. \& Knowshichrajs N. (2021). Mechanical properties of orange peel reinforced epoxy composite, International Research Journal of Modernization in Engineering Technology and Science, 3(3), 1889-1894. e-ISSN: 2582-5208

[20] Masoodi R. and Pillai K.M. (2012). A study on moisture absorption and swelling in bio-based jute-epoxy composites, Journal of Reinforced Plastics and Composites, 31(5), 285-294. https://doi.org/10.1177/0731684411434654

[21] Dhakal, H. N., Zhang, Z. A., \& Richardson, M. O. W. (2007). Effect of water absorption on the mechanical properties of hemp fibre reinforced unsaturated polyester composites. Composites science and technology, 67(7-8), 1674-1683. https://doi.org/10.1016/j.compscitech.2006.06.019.

[22] Alamri, H., \& Low, I. M. (2012). Mechanical properties and water absorption behaviour of recycled cellulose fibre reinforced epoxy composites. Polymer testing, 31(5), 620-628. https://doi.org/10.1016/j.polymertesting.2012.04.002. 
[23] Leman, Z., Sapuan, S. M., Saifol, A. M., Maleque, M. A., \& Ahmad, M. M. H. M. (2008). Moisture absorption behavior of sugar palm fiber reinforced epoxy composites. Materials \& Design, 29(8), 16661670. https://doi.org/10.1016/j.matdes.2007.11.004.

[24] Brodowsky, H., \& Mäder, E. (2007). Jute fibre/polypropylene composites II. Thermal, hydrothermal and dynamic mechanical behaviour. Composites Science and Technology,67(13), 2707-2714. https://doi.org/10.1016/j.compscitech.2007.02.011.

[25] Karmaker, A. C. (1997). Effect of water absorption on dimensional stability and impact energy of jute fibre reinforced polypropylene. Journal of materials science letters, 16(6), 462-464. https://doi.org/10.1023/A:1018508209022.

[26] Akil, H. M., Cheng, L. W., Ishak, Z. M., Bakar, A. A., \& Abd Rahman, M. A. (2009). Water absorption study on pultruded jute fibre reinforced unsaturated polyester composites. Composites Science and Technology, 69(11-12), 1942-1948. https://doi.org/10.1016/j.compscitech.2009.04.014.

[27] Gassan J and Bhedski A.K. (1999). Effect of cylic moisture absorption and desorption on mechanical properties of salinized jute-epoxy composites, Polymer Composites, 20 (4), 604-611. https://doi.org/10.1002/pc.10383

[28] Costa, F. H. M. M., \& d'Almeida, J. R. M. (1999). Effect of water absorption on the mechanical properties of sisal and jute fiber composites. Polymer-Plastics Technology and Engineering, 38(5), 1081-1094. https://doi.org/10.1080/03602559909351632

[29] Jawaid, M. H. P. S., Khalil, H. A., Khanam, P. N., \& Bakar, A. A. (2011). Hybrid composites made from oil palm empty fruit bunches/jute fibres: Water absorption, thickness swelling and density behaviours. Journal of Polymers and the Environment, 19(1), 106-109. https://doi.org/10.1007/s10924010-0203-2.

[30] Zahari W. Z., Badri R.N., Ardyananta H., Kurniawan D., Nor F.M. (2015). Mechanical properties and water absorption behavior of polypropylene/jute fiber composite by using sitarre treatment, Procedia Manufacturing, 2, 573-578. ISSN: 2351-9789

[31] Ghosh, R., Ramakrishna, A., Reena, G., Ravindra, A., \& Verma, A. (2014). Water absorption kinetics and mechanical properties of ultrasonic treated banana fiber reinforced-vinyl ester composites. Procedia Materials Science, 5, 311-315. https://doi.org/10.1016/j.mspro.2014.07.272.

[32] Alomayri, T., Assaedi, H., Shaikh, F. U. A., \& Low, I. M. (2014). Effect of water absorption on the mechanical properties of cotton fabric-reinforced geopolymer composites. Journal of Asian ceramic societies, 2(3), 223-230. https://doi.org/10.1016/j.jascer.2014.05.005.

[33] Amran, U. A., Zakaria, S., Chia, C. H., Jaafar, S. N. S., \& Roslan, R. (2015). Mechanical properties and water absorption of glass fibre reinforced bio-phenolic elastomer (BPE) composite. Industrial Crops and Products, 72, 54-59. https://doi.org/10.1016/j.indcrop.2015.01.054.

[34] Ridzuan, M. J. M., Majid, M. A., Afendi, M., Azduwin, K., Amin, N. A. M., Zahri, J. M., \& Gibson, A. G. (2016). Moisture absorption and mechanical degradation of hybrid Pennisetum purpureum/glassepoxy composites. Composite Structures, 141, 110-116. https://doi.org/10.1016/j.compstruct.2016.01.030.

[35] Hosseinihashemi, S. K., Arwinfar, F., Najafi, A., Nemli, G., \& Ayrilmis, N. (2016). Long-term water absorption behavior of thermoplastic composites produced with thermally treated wood. Measurement, 86, 202-208. https://doi.org/10.1016/j.measurement.2016.02.058.

[36] Hoto, R. E. N. E., Furundarena, G., Torres, J. P., Muñoz, E., Andrés, J., \& García, J. A. (2014). Flexural behavior and water absorption of asymmetrical sandwich composites from natural fibers and cork agglomerate core. Materials Letters, 127, 48-52. https://doi.org/10.1016/j.matlet.2014.04.088.

[37] Megiatto Jr, J. D., Ramires, E. C., \& Frollini, E. (2010). Phenolic matrices and sisal fibers modified with hydroxy terminated polybutadiene rubber: Impact strength, water absorption, and morphological aspects of thermosets and composites. Industrial Crops and Products, 31(1), 178-184. https://doi.org/10.1016/j.indcrop.2009.10.001.

[38] Hosseinaei, O., Wang, S., Taylor, A. M., \& Kim, J. W. (2012). Effect of hemicellulose extraction on water absorption and mold susceptibility of wood-plastic composites. International Biodeterioration \& 
Biodegradation, 71, 29-35. https://doi.org/10.1016/j.ibiod.2011.12.015.

[39] Manfredi, L. B., De Santis, H., \& Vázquez, A. (2008). Influence of the addition of montmorillonite to the matrix of unidirectional glass fibre/epoxy composites on their mechanical and water absorption properties. Composites Part A: Applied Science and Manufacturing,39(11), 1726-1731. https://doi.org/10.1016/j.compositesa.2008.07.016.

[40] Zhai, Z., Feng, L., Liu, Z., Zhou, S., Lou, H., \& Li, G. (2015). Water absorption and mechanical property of an epoxy composite coating containing unoxidized aluminum particles. Progress in Organic Coatings, 87, 106-111. https://doi.org/10.1016/j.porgcoat.2015.05.018.

[41] Shinoj, S., Panigrahi, S., \& Visvanathan, R. (2010). Water absorption pattern and dimensional stability of oil palm fiber-linear low density polyethylene composites. Journal of Applied Polymer Science, 117(2), 1064-1075. https://doi.org/10.1002/app.31765.

[42] Espert, A., Vilaplana, F., \& Karlsson, S. (2004). Comparison of water absorption in natural cellulosic fibres from wood and one-year crops in polypropylene composites and its influence on their mechanical properties. Composites Part A: Applied science and manufacturing,35(11), 1267-1276. https://doi.org/10.1016/j.compositesa.2004.04.004.

[43] Ramezani Kakroodi, A., Leduc, S., \& Rodrigue, D. (2012). Effect of hybridization and compatibilization on the mechanical properties of recycled polypropylene-hemp composites. Journal of Applied Polymer Science, 124(3), 2494-2500. https://doi.org/10.1002/app.35264

[44] Haque, M. M. U., Alvarez, V., Paci, M., \& Pracella, M. (2011). Processing, compatibilization and properties of ternary composites of Mater-Bi with polyolefins and hemp fibres. Composites Part A: Applied Science and 2060-2069. https://doi.org/10.1016/j.compositesa.2011.09.015.

[45] JA, M. H., Majid, M. A., Afendi, M., Marzuki, H. F. A., Hilmi, E. A., Fahmi, I., \& Gibson, A. G. (2016). Effects of water absorption on Napier grass fibre/polyester composites. Composite Structures, 144, 138146. https://doi.org/10.1016/j.compstruct.2016.02.067.

[46] Munoz E. and Garcia-Manrique J.A. (2015). Water absorption behavior and its effects on the mechanical properties of flax reinforced bio-epoxy composites, International Journal of Polymer Science, Vol. 2015, Article ID 390275, pp. 1-10. https://doi.org/10.1155/2015/390275

[47] Prabhakaran M. (2015). Design and analysis of mono leaf spring using hybrid fiber-reinforced polymer composite materials with additive as molybdenum in automobiles, Ph.D. Thesis, Faculty of Mechanical Engineering, Anna University, Chennai, India 